\title{
La crisis económico-financiera de la Argentina aumenta la mortalidad cardiovascular. ¿Estamos ante un nuevo factor de riesgo cardiovascular?
}

\author{
The economic-financial crisis in Argentina increases cardiovascular \\ mortality. Are we facing a new cardiovascular risk factor?
}

Revista Argentina de Cardioangiología Intervencionista 2019;10(2):56-57. https://doi.org/10.30567/RACI/201902/0056-0057

En este período eleccionario que estamos viviendo, inmersos en una crisis económico-financiera tremenda, donde vemos innumerables candidatos a puestos de gobierno de todos los partidos y tendencias debatir permanentemente los males que padecemos en nuestro querido país tratando de buscar los orígenes de la corrupción, la inflación, la inseguridad y tantos otros, por nombrar los principales, me permití también mirar cómo aumenta la principal causa de muerte en la Argentina por enfermedades cardiovasculares.

Desde hace unos años vienen apareciendo en el mundo reportes sobre este tema, el aumento de la mortalidad cardiovascular como consecuencia de las crisis económico-financieras. Por supuesto, la Argentina no está exenta de estas consecuencias por la crisis que estamos sufriendo.

Recientes estudios de investigación demostraron este suceso durante las crisis económicas de Grecia e Islandia, en donde también se registró el aumento de la mortalidad cardiovascular con la caída del PBI.

La pregunta que surge es: ¿La crisis económica-financiera es un nuevo factor de riesgo cardiovascular? Si bien no existen datos concluyentes, hay muchos que así lo sugieren.

En la Argentina, un estudio precursor sobre el impacto local de las crisis fue el que realizó el doctor Enrique Gurfinkel ${ }^{1}$, de la Fundación Favaloro, que analizó sus efectos a partir de 3220 hospitalizaciones ocurridas entre 1999 y 2004 y consignadas en el Global Registry of Acute Coronary Events (GRACE).

Los resultados del estudio de Gurfinkel indican que, durante el período de crisis, la incidencia de infarto de miocardio intrahospitalario fue mayor $(6,9 \%$ frente a $2,9 \% ; \mathrm{p}<0,0001)$, así como insuficiencia cardíaca congestiva ( $16 \%$ frente a $11 \% ; \mathrm{p}<0,0001)$. El tiempo de intervención con la angioplastia fue más largo durante la crisis. La proporción de incidencia de mortalidad durante la hospitalización fue del 6,2\% frente al 5,1\% después de la crisis. El odds ratio bruto para la mortalidad fue de 1,2 (intervalo de confianza del 95\%: 0,87-1,7).

Las conclusiones a las que arribó Gurfinkel son las mismas a las que llegaron los doctores Sosa Liprandi y sus colegas², que reconocen el trabajo de Gurfinkel como fuente de inspiración. Pero en el nuevo estudio, publicado en la Revista Argentina de Cardiología en el año 2012, no solo se expandió el período a analizar (1995-2005), sino que también se recurrió a una base de datos nacional (del Ministerio de Salud) sobre causas de defunción, y sus registros se compararon con la evolución del producto bruto interno (PBI) de la Argentina.

Tras analizar las tasas de mortalidad cardiovascular de los últimos treinta años, encontraron un marcado descenso, sostenido a lo largo del tiempo y que ronda el 35\%. Pero hubo dos períodos donde esas mejoras se detuvieron e, incluso, se revirtieron levemente: uno, durante la crisis del sudeste asiático, en 1997-1998; y el otro, tras la salida de la convertibilidad. En ambos casos se estableció una asociación entre el descenso del PBI del país y un aumento en la tasa de mortalidad cardiovascular y la cantidad de ACV.

En el gráfico se observa claramente cómo la caída del PBI de la curva superior es inversamente proporcional al aumento de la mortalidad cardiovascular de la curva inferior.

Los RESULTADOS de estas observaciones nos permiten decir que existió:

- Aumento de la mortalidad cardiovascular (5,4\%). En la crisis de 1998-1999 se revirtió el descenso sostenido de las defunciones por causas cardiovasculares.

- Aumento del infarto cerebral (13\%). Durante el "corralito" de 2001-2002, hubo un aumento de los ataques cerebrales en los menores de 65 años. 
La CONCLUSIÓN que podríamos especular después de estas observaciones, a las que se les sumarían los numerosos reportes sobre el tema que existen publicados, es que "las crisis económico-financieras podrían ser consideradas, de la misma manera que los desastres naturales, guerras y ataques terroristas, como un factor de riesgo de aumento de la mortalidad cardiovascular"

\section{Dr. Rubén Piraino}

Editor Asociado

Revista Argentina de Cardioangiología Intervencionista

\section{BIBLIOGRAFÍA}

1. Gurfinkel EP, Bozovich GE, Dabbous O, et al. Socio economic crisis and mortality. Epidemiological testimony of the financial collapse of Argentina. Thromb J. 2005 Dec 13:3:22.

2. Sosa Liprandi MI, Racki M, Khoury M, et al. Crisis económico-financieras en la Argentina: ¿un nuevo factor de riesgo de mortalidad cardiovascular? Rev Argent Cardiol 2012;80:137-44. 